\section{Twist or bulge?}

How does a globular protein adapt to a mutation that forces a surplus residue into a helix? J. S. Kavanaugh et al. (Biochemistry 32, 2509-2513; 1993) have looked at the structure at $1.5 \AA$ of the unstable mutant, haemoglobin Catonsville, which has a glutamate inserted into a highly conserved segment of helix ( $C$ helix). One of two things could happen: the ends could untwist to admit the intruder or the helix could bulge outwards. The $C$ helix happens to have the $3_{10}$ conformation (hydrogen-bonding to the third residue along, rather than the fourth, as in the $\alpha$-helix), and the answer is that the glutamate generates a bulge; moreover the local helix geometry switches from $3_{10}$ to $\alpha$. Kavanaugh et al. suggest that such changes in helix geometry could constitute a general mechanism of adaptation to insertions or deletions.

\section{Well spotted}

IN astronomy, the boast is often that biggest is best. But A. R. Patnaik et al. from Jodrell Bank are proud to announce the discovery of the smallest gravitational lens yet (Mon. Not. R. astr. Soc. 261, 435-444; 1993). They show that two specks, separated by just 335 milliseconds of arc in radio maps of part of the northern sky, are in fact duplicate images of the same distant radio source. An intervening galaxy, acting as a weaker gravitational lens than any yet known, has bent the source's radiation to give the two spots and - the clincher in lensing studies - an 'Einstein' ring connecting them. More than any other lens system, the pair should help cosmologists to evaluate the Hubble constant (giving the rate at which the Universe is growing) by directly tracing the geometry of space over vast distances. Perversely, doing this will require the biggest and best of radio telescope arrays.

\section{Roaring trade}

PUT one way, K. McComb et al. (Proc. R. Soc. B252, 59-64; 1993) demonstrate a direct link between a mammalian discriminatory ability and a fitness benefit. Put another, they find that lionesses with young can tell the difference between the roars of their cubs' fathers and those of unfamiliar males. The experiments, carried out in the Serengeti National Park, took the form of playing recordings of known provenance to females with cubs. The lionesses were unperturbed on hearing resident males of the pride, but instantly responded with protective behaviour when played the roars of unfamiliar males. The fitness benefit of the lionesses' reaction is plain - males entering a new social group or area often kill the existing offspring, so to further their own reproductive ambitions. data reported by Woodhead and colleagues ${ }^{1}$ is that they appear to require an upper crustal or sedimentary component in the lavas of the Pitcairn seamounts. The two principal isotopes of oxygen, ${ }^{16} \mathrm{O}$ and ${ }^{18} \mathrm{O}$, are chemically very nearly identical, but modest fractionation between them can occur when oxygen is partitioned between phases in which it is bound in very different ways. This fractionation decreases with the square of the temperature, and should be insignificant at the high temperatures of the mantle. Furthermore, the atomic environment encountered by oxygen in different mantle minerals and melts is similar. Thus significant fractionation of $O$ isotopes occurs only at the surface of the Earth. Pitcairn seamount lavas have $\mathrm{O}$ isotope ratios up to a few parts per million higher than the mantle value, which leads to the virtually inescapable conclusion that they contain a component that was once at the surface of the Earth.

The only real alternatives to the Pitcairn plume containing recycled continental or sedimentary material are that the magmas have assimilated sediment in crustal magma chambers or they have exchanged oxygen during subsequent submarine weathering. In this respect, it is somewhat disturbing that the highest, least mantle-like $\mathrm{O}$ isotope ratios occur in lavas that apparently experienced extensive fractional crystallization. The extensive crystallization implies shallow magma storage and hence the opportunity to assimilate surrounding rock. The nature of the correlations between $\mathrm{O}$ isotope ratios and $\mathrm{Sr}, \mathrm{Nd}$ and $\mathrm{Pb}$ isotope ratios is not consistent with assimilation, and the correlation between $\mathrm{O}$ and $\mathrm{Nd}$ isotope ratios almost certainly could not result from weathering. Nevertheless, the great potential significance of these results makes one hope that the authors will soon provide the types of data, such as $\mathrm{H}_{2} \mathrm{O}$ analyses and $\mathrm{O}$ isotope analyses of phenocrysts, that could completely rule out assimilation and weathering.

As Woodhead and colleagues point out, the strong correlations between radiogenic and $\mathrm{O}$ isotope ratios imply recent mixing between the sedimentary and mantle components. This suggests that the subducted sediment somehow survived as a chemically and physically distinct region large enough to avoid obliteration by diffusion. Another intriguing result is the sediment/mantle concentration ratios of $\mathrm{Sr}, \mathrm{Nd}$ and $\mathrm{Pb}$ inferred from the curvature of the radiogenic-isotope-O-isotope arrays. The sedimentary component appears to be richer in $\mathrm{Sr}$, slightly richer in $\mathrm{Nd}$, and poorer in $\mathrm{Pb}$ than modern clay-rich marine sediments.

Carbonate sediment would provide a closer, though still imperfect, match, a reminder that deep mantle recycling and mantle plumes may play a role in longterm climate regulation. Mantle plumes add $\mathrm{CO}_{2}$ to the atmosphere-hydrosphere system, while sediment subduction removes it. If this sediment were carbonate-rich, it might imply a short cycle time because carbonate deep-sea sediment was rare before 600 million years ago. But estimates of the timescale of deep mantle recycling, initially around 2,000 million years, have been growing shorter anyway.

\section{Heating}

The initial estimate was based partly on the time required for radioactive heating to cause the subducted oceanic crust and sediment to become buoyant and rise $^{4}$. It now appears that radioactive heating would be less important than conductive heating from the core, allowing a faster cycle time. If the seismically peculiar $\mathrm{D}^{\prime \prime}$ layer at the base of the mantle is the source of plumes, as some geophysicists now suspect (for example, ref. 10), its volume is such that the present plume flux would exhaust it in a few hundred million years, implying that proto-plume material is quickly cycled through the layer. Class et al. ${ }^{8}$ have also concluded that the cycle time is short. They argue that isotopic variations in lavas produced over the past 100 million years by the Kerguelen mantle plume require a cycle time of much less than a thousand million years.

Clearly, there are many issues surrounding the origin of mantle plumes and the fate of subducted sediment that remain to be resolved. Although it might be too much to say that Woodhead and colleagues have found the proverbial smoking gun that settles the issue of deep mantle recycling, they do seem at least to have found a gun. Whether it has been recently fired will only be shown with a few additional laboratory tests. There will be some lingering doubts, but the work of Woodhead and others represents some of the strongest evidence yet for this grandest of geochemical cycles.

William M. White is in the Department of Geological Sciences, Cornell University, Ithaca, New York 14853, USA.

\footnotetext{
1. Woodhead, J. D., Greenwood, P., Harmon, R. S. \& Stoffers, P. Nature 362, 809-813 (1993).

2. Davies, G. F. J. geophys. Res. 93, 10467-10480 (1988).

3. Schilling, J.-G. Nature 242, 565-571 (1973).

4. Hofmann, A. W. \& White, W. M. Earth planet. Sci. Lett. 57, 421-436 (1982)

5. Armstrong, R. L. Rev. Geophys. 6, 175-199 (1968)

6. Plank, T \& Langmuir, C. H. Nature 362. 739 (1993).

7. McKenzie. D. P. \& O'Nions, R. K. Nature 301, 229-231 (1983).

8. Class, C., Goldstein, S. L., Galer, S. J. G. \& Weis, D. Nature 362, 715-721 (1993).

9. White, W. M. Geology 13, 115-118 (1985).

10. Davies, G. F. \& Richards, M. A. J. Geol. 100, 151-206 (1993)
}

ㄷ 1993 Nature Publishing Group 